\title{
TECHNOLOGICAL ASPECTS IN FABRICATION OF MICRO- AND NANO-SIZED CARBON BASED FEATURES: NANORODS, PERIODICAL ARRAYS AND SELF-STANDING MEMBRANES
}

\author{
Tibor Ižák * Mária Domonkos *,**_ Oleg Babchenko \\ Marián Varga ${ }^{*}$ _ Bohuslav Rezek ${ }^{*}$ _ Vlastimil Jurka* \\ Karel Hruška * Alexander Kromka ${ }^{*}$,**
}

\begin{abstract}
Diamond and/or carbon thin films are in the center of interest due to their variability and extraordinary combination of intrinsic properties. However, some applications require fabrication of films with tailored properties. Especially, fabrication of periodic structures is highly attractive due to their increased surface area. In this contribution we point out the key technological aspects for fabrication of micro- and nano-sized carbon-based structures. Three representative structures are presented: diamond nanorods, self-assembled templates and self-standing diamond membranes. We found that the diameter of diamond nanorods can be controlled in a broad range from 10 to $200 \mathrm{~nm}$ by the masking material ( $\mathrm{Au} v s \mathrm{Ni})$ and its initial thickness (from few to tens of nanometers). The assembly of polystyrene microspheres in mono- or multi-layer with square or hexagonal periodicities was controlled by the spin-coating parameters. The diamond porous membrane was selectively grown on Si substrate with an interdigital or mesh like geometry. Advantages of each structure as well as the fabrication limitations are discussed more in detail and finally their representative applications are pointed out.
\end{abstract}

K e y w or d s: diamond, carbon, nanorods, microsphere lithography, selective area deposition, SEM

\section{INTRODUCTION}

Diamond and carbon thin films due to their variability and superior mechanical, optical, electrical, and biocompatible properties, become widely used over the world in multi-disciplinary fields such as material engineering (composite materials), opto-electronics (electronic devises, sensors), bio-chemistry (catalysts), life science (implants, drug delivery, bio-labelling) or even microbiology (as anti-adhesive and antibacterial coatings) [1-5]. For each scientific or commercial field, intrinsic properties have to be often tailored to meet specific requirements on surface morphology, electrical conductivity, optical transparency, etc. Especially, for life science and (bio-) sensoric applications these requirements include tailorable material morphology/topology and surface area as large as possible [6]. Various pre- or post growth techniques have been developed to fabricate surfaces of wished features. Only briefly, these techniques include reactive ion etching $[7,8]$ involving EBL $[9]$, ink-jet printing of diamond seeds [10], selective area deposition $[11,12]$ including selective etching of substrate [13]. However, only a limited number of above mentioned techniques allows the fabrication of geometrically ordered arrays or templates. Moreover, some of them are too complex and expensive for industrial applications.

In this contribution we review the fundamental technological aspects needed for the fabrication of diamond nanorods, self-assembled arrays (templates) and self- standing diamond membranes. Some technological procedures represent a simple way to fabricate the geometrically ordered diamond arrays, or even hierarchically structured morphologies where micro- and nano-sized features are combined within one substrate. The fabricated surface features are characterized by SEM and Raman measurements.

\section{EXPERIMENTAL}

\subsection{Fabrication of diamond nanorods}

Polycrystalline diamond thin films with the thickness of $\sim 1.6 \mu \mathrm{m}$ were grown by microwave plasma enhanced chemical vapor deposition system with an ellipsoidal cavity resonator on Si substrates [14]. After then, thin metal films $(\mathrm{Au}$ or $\mathrm{Ni})$ with different thickness $(2-15 \mathrm{~nm})$ were thermally evaporated on diamond films and treated in hydrogen rich microwave plasma $\left(\right.$ at $500{ }^{\circ} \mathrm{C}$ for $10 \mathrm{~min}$ ). This treatment resulted in the formation of nano-sized metal droplets on diamond surface [15]. The formed metal droplets were used as the masking material during the capacitively coupled plasma reactive ion etching (CCPRIE) in $40 \%$ of $\mathrm{CF}_{4}$ in $\mathrm{O}_{2}$ for $10 \mathrm{~min}$ at $0.12 \mathrm{mbar}$ and $100 \mathrm{~W}$ [27]. Raman measurements, not shown here, confirmed the diamond character for all samples used in this study.

\footnotetext{
* Institute of Physics, Czech Academy of Sciences v.v.i, Cukrovarnická 10, 16200 Prague 6, Czech Republic ${ }^{* *}$ Department of Physics, Faculty of Civil Engineering, Czech Technical University in Prague, Thákurova 7, 16629 Prague 6, Czech Republic, kromka@fzu.cz
} 


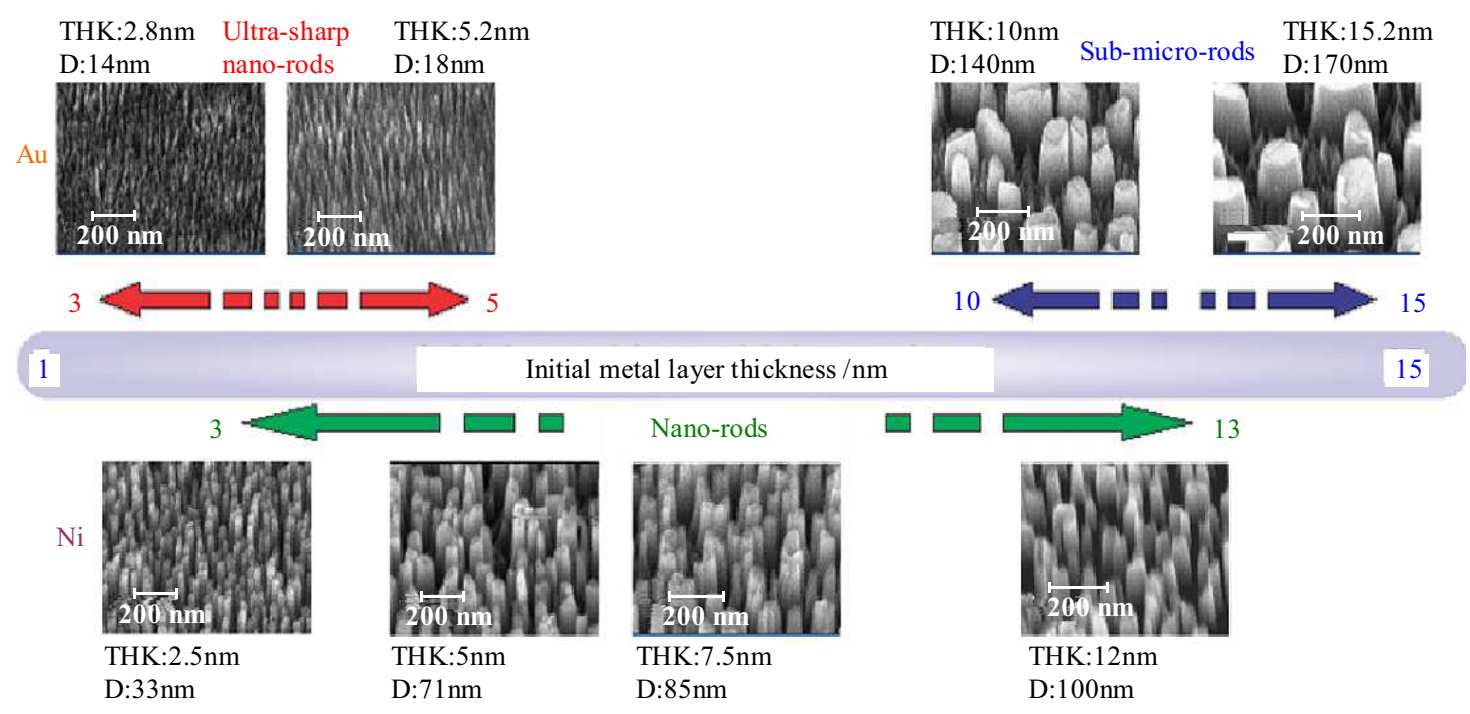

Fig. 1. Surface morphology of diamond films after reactive ion etching using different self-assembled metal droplets as the mask. Notes: (i) - SEM images are shown at angle $45^{\circ}$; (ii) — abbreviations: THK — initial thickness of the metal layer, D — diameter of nano/microrods, scale bar represents $200 \mathrm{~nm}$ for all samples

\subsection{Fabrication of periodical arrays}

Self-assembled arrays of polystyrene microspheres (PSM) were obtained by using a spin-coating. Two types of monodispersed PSMs with the diameter of $500 \mathrm{~nm}$ diluted in deionized (DI) water were used: i) $1 \mathrm{wt} \%$ (from Phosphorex Inc., USA) and ii) $5 w t \%$ (from microParticles $\mathrm{GmbH}$, Germany). First, Si substrates $\left(10 \times 10 \mathrm{~mm}^{2}\right)$ were ultrasonically cleaned in isopropyl alcohol, then treated in oxygen plasma to make the surface hydrophilic. The aqueous dispersion of PSM ( $5 w t \%)$ was further diluted in Triton X-100/methanol solution (1:400) at ratio of $1: 2$ and then $70 \mu \mathrm{l}$ of the final dispersion was dropped onto the Si substrates. The spin-coating process was performed for $2 \mathrm{~min}$ at rotation speed of $8000 \mathrm{rpm}$ with acceleration of $1000 \mathrm{rpm} / \mathrm{s}$. A schematic overview of the spin-coating process is shown in Fig. 2a. In addition, PSM arrays were also spin-coated on diamond thin films and exposed to the etching in CCP-RIE [16].

\subsection{Fabrication of self-standing diamond mem- branes}

The self-standing membranes consisting of diamond bridges (beams) were fabricated by the selective area deposition. First, the Si substrate $\left(10 \times 10 \mathrm{~mm}^{2}\right)$ was spincoated with a negative polymer (ma-N-1410) and dried at $100{ }^{\circ} \mathrm{C}$ for 2 minutes. Then the polymer coated Si substrate was processed by a two-step optical lithography process which defined the diamond "frame" $\left(8 \times 8 \mathrm{~mm}^{2}\right)$ and interconnected with diamond bridges $(200 \mu \mathrm{m}$ wide and $5 \mu \mathrm{m}$ in length). After that, the ultrasonic treatment was done for $10 \mathrm{~min}$ in the water-based solution with diamond powder. Employing the lift-off technique, the diamond nano-seeds were selectively removed from unwished areas. The diamond growth was carried out in the focused microwave CVD system at following parameters: a) initial growth at MW power of $2 \mathrm{~kW}$, total gas pressure of
$5 \mathrm{kPa}$, gas mixture $2 \% \mathrm{CH}_{4}$ in $\mathrm{H}_{2}$ and b) fast growth at $5 \mathrm{~kW}, 15 \mathrm{kPa}, 3 \% \mathrm{CH}_{4}+2 \% \mathrm{CO}_{2}$ in $\mathrm{H}_{2}$. To eliminate the spontaneous (or parasitic) diamond growth on the non-nucleated areas, the diamond growth was repeatedly combined with the wet etching of Si substrate to remove spontaneously formed diamonds grown on un-whished areas. Finally, the diamond membrane was formed by wet etching of Si substrate. Other technological details on the selective area deposition of mesh-like geometry are summarized in our previous works [17].

\subsection{Characterization of diamond films}

The grain size, surface morphology and cross-section views of diamond and carbon films were investigated by scanning electron microscopy — SEM, employing e_LiNE writer (Raith GmbH) or MAIA 3 (Tescan). Surface topography measurements were performed in the tapping mode on ICON AFM (Bruker). The diamond character of the samples was studied by Renishaw InVia Reflex Raman spectrometer with the excitation wavelengths of 325 and $442 \mathrm{~nm}$.

\section{RESULTS AND DISCUSSION}

\subsection{Diamond nanorods}

Figure 1 shows surface morphologies of diamond films after the reactive ion etching step. The morphology varies from ultra-sharp nano-rods to sub-micro rods depending on the used metal ( $\mathrm{Au}$ or $\mathrm{Ni}$ ) and its initial thickness. As found the thin gold layer (thickness $<5 \mathrm{~nm}$ ) is preferable masking material for formation of very dense and ultra-sharp diamond nano-rod arrays. The formation of perpendicular rods in diameter varied from 140 to $170 \mathrm{~nm}$, also labeled as sub-micro-rods, was achieved by employing Au mask of initial thickness of $10 \div 15 \mathrm{~nm}$. The plasma assisted thermal treatment of $\mathrm{Au}$ layers thicker 


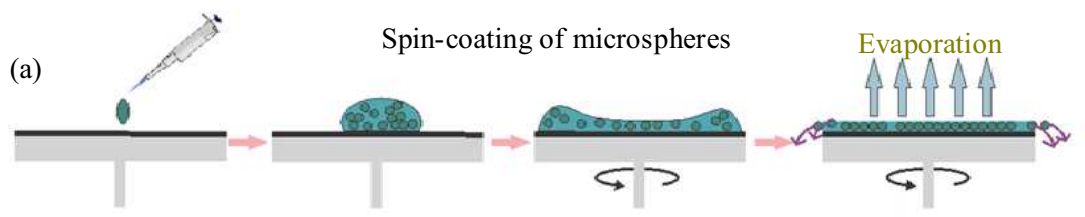

(b) Low coverage

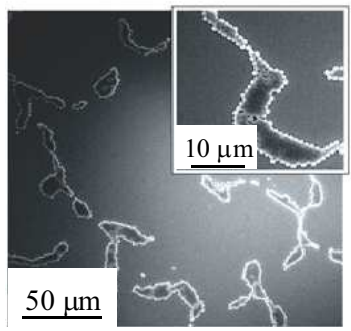

Low concentration (c) Mono- layer

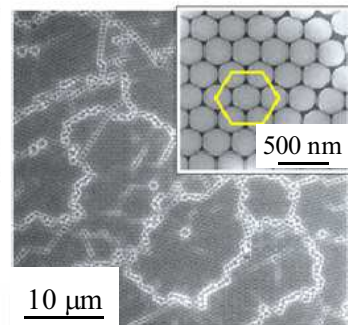

Optimal concentration (d) Multi-layer assembly

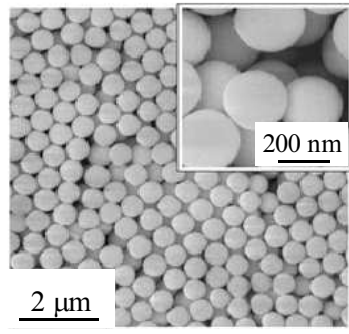

Low rotation

too high concetration

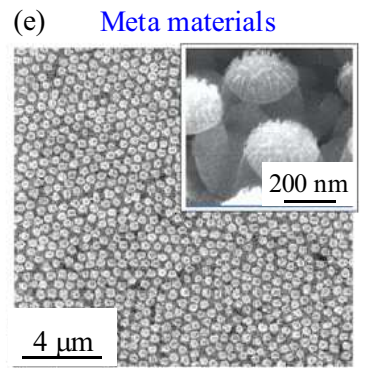

Plasma etched

PSM on diamond

Fig. 2. Schematic view of spin coating of PS microspheres. High and low magnification SEM images of PS microsphere dispersed on silicon (b-d) and diamond thin film after reactive ion etching (e)

than $15 \mathrm{~nm}$ resulted in the formation of irregular clustered like Au structures which were not suitable for fabrication of diamond nanorod arrays. In contrast to $\mathrm{Au}$, using a nickel thin layer $(3 \div 13 \mathrm{~nm})$ allows the fabrication of diamond nano-rods arrays with "medium" diameter varied from 33 to $100 \mathrm{~nm}$. We were not able to fabricate sharper diamond nanorods due to limited de-wetting of $\mathrm{Ni}$ droplets [18]. Using thicker Ni layers (> $18 \mathrm{~nm}$ ) did not result in periodically ordered droplets, as similarly observed for Au layer thicker than $15 \mathrm{~nm}$. We found that the formation of $\mathrm{Au}$ or $\mathrm{Ni}$ droplets was negligibly influenced by the substrate material (silicon, diamond, silicon dioxide). However, treatment temperature higher than $350^{\circ} \mathrm{C}$ was needed to form metal droplets. Expect of the temperature effect, enough high dense hydrogen rich plasma was the additional key process parameter needed to form self-assembled droplets from metals initially thicker than $10 \mathrm{~nm}$. Chang and coworkers have proposed that the dominant droplet formation mechanism in hydrogen rich microwave plasma is the plasma-enhanced coalescence, where the hydrogen plasma etching only acts at the "cracking" of the metal film [19].

\subsection{Self-assembled templates}

Even spin-coating technique has a number of advantages (such as simplicity, low cost, time efficiency, etc) the fabrication of microsphere monolayer is not a trivial task. Except the process parameters $i e$ rotation speed, acceleration or time) the initial concentration of dispersion is found as key parameter to assemble microspheres into monolayer. It means that low concentration of dispersion ( $1 w t \%$ ) is not enough to achieve fully closed homogeneous PSM arrays regardless of the spin-coating process parameters (see Fig. 2b). However, increased concentration of dispersion (initially $5 w t \%$ ) and optimized process parameters resulted in the formation of the compact monolayer with hexagonal ordering and relatively low density of defects (see Fig. 2c). Too low rotation speed $(<1000 \mathrm{rpm})$ leads to the formation of multi-layers (Fig. 2d). The same effect had too short process time. On the other hand, too high rotation speed or acceleration rate do not lead to formation of fully-closed monolayer. It was further observed that using multistep (ie first $20 \mathrm{~s}$ at $200 \mathrm{rpm}, 1 \mathrm{~min}$ at $8000 \mathrm{rpm}$ ) spin-coating is better for a successful fabrication of monolayers. The self-assembled monolayer of PSM can be easily structured by reactive ion etching, which allows a control of PSM shape, diameter and gaps between them. The periodicity is controlled by the initial size of PSMs which are commercially available in a wide range from few $\mathrm{nm}$ up to $300 \mu \mathrm{m}$. Such tailored arrays was used as the template for diamond thin film structuring.

\subsection{Self-standing diamond membranes}

Figure 3 shows surface morphology and Raman spectra of self-standing diamond membrane. Optical and SEM images (Fig. 3a-b) reveal the growth of long bridges ( $200 \mu \mathrm{m}$ in width) both-side fixed to the outside frame. The thickness of formed bridges was $8 \mu \mathrm{m}$, as measured from the cross section view (Fig. 3c). For the SEM and Raman measurements, the membrane was fixed to carrier silicon substrate with polymer. Raman spectra of formed bridges are dominated by the diamond characteristic peak centered at $1332 \mathrm{~cm}^{-1}$ (Fig. 3d).

The area between the bridges is dominated by the $\mathrm{Si}$ carrier substrate with the peak at $520 \mathrm{~cm}^{-1}$ — the green line in Fig. 3d. The diamond bridge was measured from the back-side (blue and red lines). The Raman spectrum from the bridge back side reveals a weak signal from the silicon. In this case, the $\mathrm{Si}$ signal is attributed to the remaining silicon coming from the primary used substrate for the diamond growth. Surface morphology from the bridge back-side reveals diamond clusters in size up to $50 \mathrm{~nm}$. SEM image from the top side shows well-facetted diamond crystals in size $58 \mathrm{~m}$. Based on this observation and cross-section view, the diamond growth follows the so 
(a)

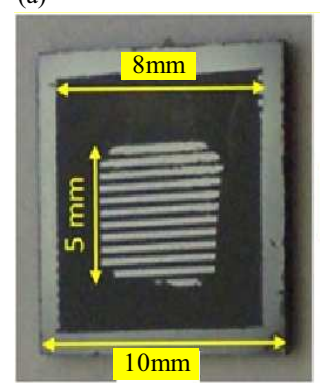

Intensity (au)

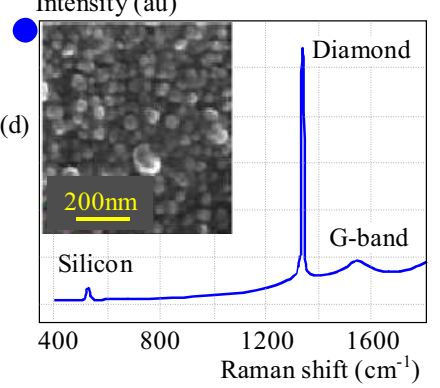

(b)

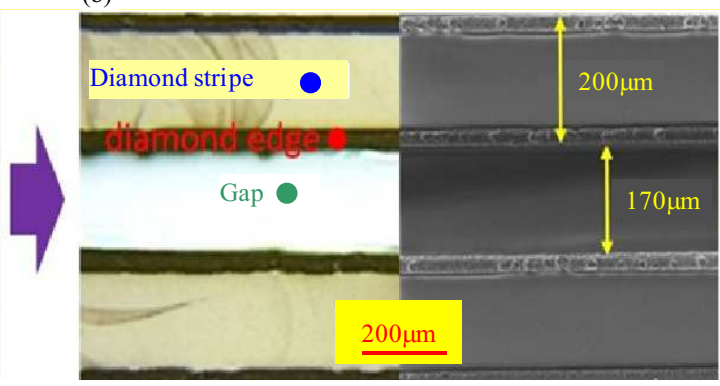

Intensity (au)

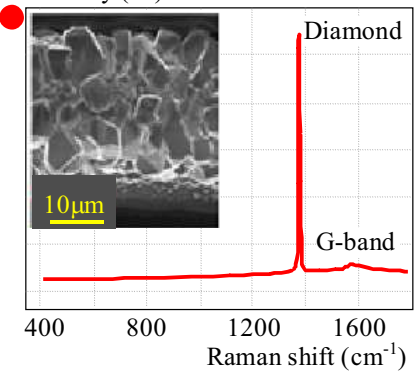

(c)

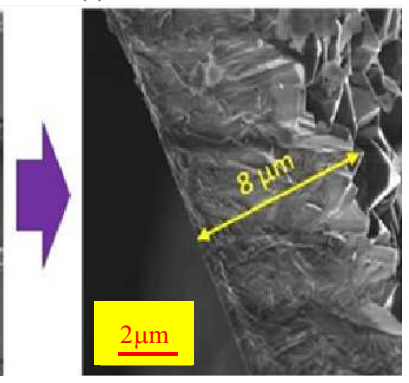

Intensity (au)

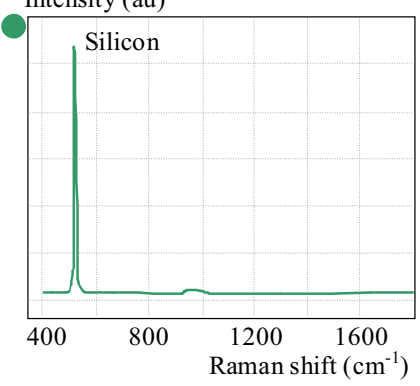

Fig. 3. Optical, SEM images and Raman spectra of self-standing diamond membrane with detailed view of individual diamond bridges (strips)

called evolutionary selection growth mode where crystals with the highest growth rate survive and continue the growth [20].

\section{CONCLUSION}

This work reviewed a technological progress in understanding and controllable fabrication a broad range of micro/nano-sized structures from allotrope carbon forms. The usability of such structures has been demonstrated by our previous works. For example, the diamond nanorods enhanced the detection sensitivity to gases [21] and biomolecules [22]. The spin-coated polystyrene microspheres confirmed their usability for structuring or growth of diamond periodical arrays [16]. The structured PS microspheres were used for Surface Enhanced Raman spectroscopy (SERS). Similarly, the $\mathrm{SiO}_{2}$ microspheres were built in diamond layer and after their wet etching, spherical voids were formed in the diamond films which should be potentially attractive as meta materials with a periodically variable index of refraction. Moreover, the structured PS microspheres deposited on the diamond surface represent a hierarchical surface combining nano-sized soft material on micro-rough hard surface (diamond). We propose that such soft-hard/nano-micro surface is attractive as the artificial substrate for life science or as an anti-adhesive/antibacterial coating. The self-standing thin diamond membranes in bridge or mesh geometry offer not yet explored variability of experiments in which the diamond surface directly interacts with the flowing liquid medium allowing dynamic cultivation studies with bacteria, cells, or (bio) molecules. In such applications, the stress-free engineered management is the crucial issue for fabrication mechanically stable self-standing diamond bridges, beams or cantilevers. As challenging technological part it is still remaining the fabrication of a broad range of structures with aspect ratio as high as possible. Presently, our research focuses on investigation of advanced properties of structured diamond or other carbon forms.

\section{Acknowledgements}

This work was supported by the GACR project 15 01687S and SGS14/111/OHK1/2T/11. Special acknowledgement to Pavla Bauerova for SEM measurements. This work occurred in frame of the LNSM infrastructure.

\section{REFERENCES}

[1] NEBEL, C. E.-REZEK, B.-SHIN, D.-UETSUKA, H.YANG, N.: Diamond for Bio-Sensor Applications, Journal of Physics D: Applied Physics 40 No. 20 (2007), 6443-6466.

[2] MERSON, T. D.-CASTELLETTO, S.-AHARONOVICH, I.-TURBIC, A.-KILPATRICK, T. J.-TURNLEY, A. M.: Nanodiamonds with Silicon Vacancy Defects for Nontoxic Photostable Fluorescent Labeling of Neural Precursor Cells, Optics Letters 38 No. 20 (2013), 4170-4173.

[3] BERANOVÁ, J.-SEYdLOVÁ, G.-KOZAK, H.-POTOCKÝ, Š.-KONOPÁSEK, I.-KROMKA, A. : Antibacterial Behavior of Diamond Nanoparticles against Escherichia Coli, Physica Status Solidi (b) 249 No. 12 (2012), 2581-2584.

[4] KAWAKITA, J.-HASHIMOTOSHINODA, Y.-SAKAMOTO, Y.: Electrochemically Catalytic Activity of Boron-doped Diamond for I-/I0 Redox Couple, Electrochemistry 83 No. 05 (2015), 342-344.

[5] GRAusova, L.-BACAKOVA, L.-KROMKA, A.-POTOCKY, S.-VANECEK, M.-NESLADEK, M.-LISA, V. : Nanodiamond as Promising Material for Bone Tissue Engineering, Journal of Nanoscience and Nanotechnology 09 No. 06 (2009), 3524-3534.

[6] SZUNERITS, S.-COFFINIER, Y.-BOUKHERROUB, R. : Diamond Nanowires: A Novel Platform for Electrochemistry 
and Matrix-Free Mass Spectrometry, Sensors 15 No. 06 (2015), $12573-12593$.

[7] HISCOCKS, M. P.-KAALUND, C. J.-LADOUCEUR, F.HUNTINGTON, S. T.-GIBSON, B. C.-TRPKOVSKI, S.SIMPSON, D.-AMPEM-LASSEN, E.-PRAWER, S.-BUTLER, J. E. : Reactive Ion Etching of Waveguide Structures in Diamond, Diamond and Related Materials 17 No. 11 (2008), 1831-1834.

[8] WANG, Q.-QU, S. L.-FU, S. Y.-LIU, W. J.-LI, J. J.-GU, C. Z.: Chemical Gases Sensing Properties of Diamond Nanocone Arrays Formed by Plasma Etching, Journal of Applied Physics 102 No. 10 (2007), 103714.

[9] ONDIČ, L.-BABCHENKO, O.-VARGA, M.-KROMKA, A.-ČTYROKÝ, J.-PELANT, I. : Diamond Photonic Crystal Slab: Leaky Modes and Modified Photoluminescence Emission of Surface-Deposited Quantum Dots, Scientific Reports 2 No. 914 (2012).

[10] CHEN, Y. C.-TZENG, Y.-DAVRAY, A.-CHENG, A. J.RAMADOSS, R.-PARK, M.: Fabrication of Diamond Micro-Structures by Ink-Jet Printed Diamond Seeding and Microwave Plasma Assisted Chemical Vapor Deposition, Diamond and Related Materials 17 No. 4-5 (2008), 722-727.

[11] BONGRAIN, A.-SCORSONE, E.-ROUSSEAU, L.-LISSORGUES, G.-GESSET, C.-SAADA, S.-BERGONZO, P. : Selective Nucleation in Silicon Moulds for Diamond MEMS Fabrication, Journal of Micromechanics and Microengineering 19 No. 07 (2009), 074015.

[12] LIU, H.-WANG, C.-GAO, C.-HAN, Y.-LUO, J.-ZOU, G.-WEN, C.: New Insights into Selected-Area Deposition of Diamond Films by Means of Selective Seeding, Journal of Physics: Condensed Matter 14 No. 44 (2002), 10973-10977.

[13] HIRABAYASHI, K.-TANIGUCHI, Y.-TAKAMATSU, O.IKEDA, T.-IKOMA, K.-IWASAKI-KURIHARA, N. : Selective Deposition of Diamond Crystals by Chemical Vapor Deposition using a Tungsten-Filament Method, Applied Physics Letters 53 No. 19 (1988), 1815.

[14] MORTET, V.-KROMKA, A.-KRAVETS, R.-ROSA, J.VORLICEK, V.-ZEMEK, J.-VANECEK, M. : Investigation of Diamond Growth at High Pressure by Microwave Plasma Chemical Vapor Deposition, Diamond and Related Materials 13 No. 4-8 (2004), 604-609.

[15] BABCHENKO, O.-KROMKA, A.-HRUSKA, K.-MICHALKA, M.-POTMESIL, J.-VANECEK, M. : Nanostructuring of Diamond Films using Self-Assembled Nanoparticles, Central European Journal of Physics 7 No. 02 (2009), 310-314.

[16] DOMONKOS, M.-IŽÁK, T.-ŠTOLCOVA, L.-PROŠKA, J.-DEMO, P.-KROMKA, A. : Structuring of Diamond Films using Microsphere Lithography, Acta Polytechnica 54 No. 05 (2014), 320-324.

[17] VARGA, M.-BABCHENKO, O.-BAUEROVA, P.-HRUSKA, K.-JURKA, V.-KROMKA, A.-REZEK, B.: Fabrication of 3D Diamond Membranes for Microfluidic Systems, NANOCON (2015), 556-562.

[18] JANSSEN, W.-GHEERAERT, E. : Dry Etching of Diamond Nanowires using Self-Organized Metal Droplet Masks, Diamond and Related Materials 20 No. 03 (2011), 389-394.

[19] CHANG, S. C.-LIN, T. C.-LEE, J. H. : Converting Nickel Film to Nano Particles using Hydrogen Plasma Treatment, Solid State Technology 50 No. 11 (2007), 44.

[20] YIN, Z.-TAN, H. S.-SMITH, F. W.: Determination of the Optical Constants of Diamond Films with a Rough Growth Surface, Diamond and Related Materials 05 No. 12 (1996), 1490-1496.

[21] DAVYDOVA, M.-KROMKA, A.-REZEK, B.-BABCHENKO, O.-STUCHLIK, M.-HRUSKA, K. : Fabrication of Diamond Nanorods for Gas Sensing Applications, Applied Surface Science 256 No. 18 (2010), 5602-5605.

[22] KOZAK, H.-BABCHENKO, O.-ARTEMENKO, A.-UKRAINTSEV, E.-REMES, Z.-REZEK, B.-KROMKA, A. :
Nanostructured Diamond Layers Enhance the Infrared Spectroscopy of Biomolecules, Langmuir 30 No. 8 (2014), 2054-2060.

Received 17 August 2015

Tibor Ižák (MSc, PhD) graduated in microelectronics in 2006 and in 2012 he received his $\mathrm{PhD}$ in the same field at Slovak University of Technology in Bratislava. From 2008 he is a researcher at Institute of Physics, Czech Academy of Sciences in Prague. His research topics include mainly material science (thin films \& carbon technology), sensorics, and impedance spectroscopy.

Mária Domonkos (MSc) graduated in Optics and Nanostructures from the Czech Technical University (CTU) in Prague, Faculty of Nuclear Science and Physical Engineering in 2014. She is currently a PhD student at CTU. Her research activity at CTU and Institute of Physics of the Czech Academy of Sciences focuses on growth and structuring of carbon-based materials.

Oleg Babchenko (MSc, $\mathrm{PhD}$ ) received his MSc in Pedagogic and Methodic of Education, Physics at Zhytomyr State University (Ukraine) in 2005. In 2014 he received $\mathrm{PhD}$ degree in Physical Engineering at Czech Technical University, Prague. His research interest is focused on carbon nanomaterials (carbon nanostructures, diamond thin films) including growth, processing, characterization and application.

Marián Varga (MSc, PhD) graduated in microelectronics in 2008 and received his $\mathrm{PhD}$ in 2013, both at Slovak University of Technology. He is engaged in CVD technology focused on fabrication of carbon materials/composites, and analyses such as SEM, Raman and optical measurements.

Bohuslav Rezek (Doc, RNDr, PhD) graduated from Physics at the Faculty of Mathematics and Physics at the Charles University in Prague in 1996. In 2001 he obtained PhD at the Academy of Sciences of the Czech Republic (ASCR) doing research on diamond and its interfaces in Germany, Switzerland and Japan. He was research team leader and Purkyne Fellow at the Institute of Physics ASCR focused on nano-interfaces of semiconductors and organic materials towards opto-electronic and bio-electronic applications.

Vlastimil Jurka (MSc) graduated in chemistry - University of Chemical Technology in Prague. He is a specialist in photolithographic and e-beam lithographic techniques for research and development of semiconductor devices: LEDs on the GaAsP and Gap, silicon CMOS ICs, semiconductor sensors and particle detectors, processing varies epitaxial heterostructures, graphene and diamond films.

Karel Hruška (dipl Ing) in 1985 graduated in electrochemical engineering, Electrotechnical faculty CTU, Prague. In years 1985-92 he worked at Research Institute for Radiocommunication and $1992-2005$ at MIKROTEK Ltd. From 2005 up to now he works at Institute of Physics (Academy of Sciences of Czech Republic in Prague). He is a specialist in optical and electron beam lithography.

Alexander Kromka (MSc, PhD), born in Nitra in 1971, received his MSc degree in electronic engineering from the Slovak Technical University, Bratislava, in 1995 and received the doctoral degree in 2001. In 2009 he became a research team leader and Purkyne Fellow at the Institute of Physics ASCR. His research is focused on microwave plasma CVD growth of diamond thin films, carbon nanowalls and CNT, their plasma functionalization/structuring and developing carbon based devices. 